\title{
Optimization of wind energy conversion systems - an artificial intelligent approach
}

\author{
Ying Ying Koay, Jian Ding Tan, Siaw Paw Koh, Kok Hen Chong, \\ Sieh Kiong Tiong, Janaka Ekanayake \\ Institute of Sustainable Energy, Universiti Tenaga Nasional, Malaysia
}

\begin{tabular}{l} 
Article Info \\
\hline Article history: \\
Received Oct 18, 2019 \\
Revised Dec 28, 2019 \\
Accepted Jan 17, 2020 \\
\hline Keywords: \\
Electromagnetism-Like \\
Mechanism Algorithm \\
Maximum Power Point \\
Tracking \\
Split-Probe-Compare \\
Wind Energy Conversion \\
System
\end{tabular}

Article Info

Article history:

Received Oct 18, 2019

Revised Dec 28, 2019

Accepted Jan 17, 2020

\section{Keywords:}

Mechanism Algorithm

Maximum Power Point

Split-Probe-Compare

System

\begin{abstract}
The environmentally friendly wind energy conversion system has become one of the most studied branches of sustainable energy. Like many other power generator, maximum power point tracking is an easy yet effective way to boost the efficiency of the conversion system. In this research, a modified Electromagnetism-like Mechanism Algorithm (EM) is proposed for the maximum power point tracking (MPPT) scheme of a micro-wind energy conversion system (WECS). In contrast with the random search steps used in a conventional EM, modified EM is enhanced with a Split, Probe, and Compare (SPC-EM) feature which ensures solutions with higher accuracies quicker by not having to scrutinize the search in details at the beginning stages of the iterations. Experiments and simulations are carried to test the SPC-EM in tracking the maximum power point under different wind profiles. Results indicate that the performance of the modified EM showed significant improvement over the conventional EM in the benchmarking. It can thus be concluded that based on the simulations, the SPC-EM performs well as an MPPT scheme in a micro-WECS.
\end{abstract}

This is an open access article under the CC BY-SA license.

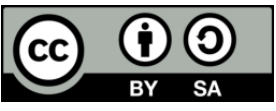

\section{Corresponding Author:}

Jian Ding Tan, Institute of Sustainable Energy, Universiti Tenaga Nasional, Jalan Ikram-Uniten, 43000 Kajang, Selangor, Malaysia.

Email: tjianding@uniten.edu.my

\section{INTRODUCTION}

Fossil fuels based power generation has always raised environmental concerns. Researchers around the world are racing in search for alternative sources with less environmental impacts. With it comes a rapid development of renewable energy studies [1-5]. Renewable energy can generally be divided into several major branches. Among others is the wind energy. Wind energy is known to be one of the most environmental friendly and quickly developing source of electricity nowadays [6-8]. In a wind energy conversion system (WECS), the overall efficiency is generally tied to the ability of the system to abstract maximum output power at all instant in a wide range of wind speed [9]. In order to grant the WECS with maximum output power, a maximum power point tracking (MPPT) mechanism is crucial to bring the turbine to the maximum power point (MPP) for all wind speed values.

Many MPPT mechanisms are proposed in the literature. Incremental conductance (IC) algorithm, for instance, does not require sensors and details on the turbine and generator, thus making it more reliable and less expensive [10-13]. Hill climbing (HC) algorithm applies a different strategy which relies heavily on mathematical optimization approach to find the local optima of a given function [14-18]. In this method, if the current solution is on the right of the best optima, the switching moves the operating point to the left, 
making it nearer to the optima, and vice versa. The general plan of the $\mathrm{HC}$ is based on changing a control variable in a determined step size and analyze the resulting changes in the outcome, until there is no more improvement [19-21]. HC can be widely found in the MPPT studies [22-25]. However, in a rapid wind variation, $\mathrm{HC}$ can be sluggish and head in the wrong direction to the MPP [26]. Other MPPT algorithms for WECS, such as the perturb and observe $(\mathrm{P} \& \mathrm{O})$ algorithm aims to maximize the generated power output while cutting down the reliance on control units and sensors [27, 28].

In this paper, a modified Electromagnetism-Like Mechanism (EM) algorithm is proposed as the DPC MPPT mechanism of a micro WECS. The contribution of this paper is two-fold and can be summarized along the lines as followed. First, a modified EM algorithm with Split, Probe, and Compare (SPC) feature is proposed. With this feature, this global optimization algorithm is enhanced with the ability to find solutions with relatively higher accuracies in shorter time. Secondly, the modified EM is tested in simulation to track for the maximum power point of a WECS. The paper is presented in five chapters. Chapter Two explains the work mechanism of the EM and the details of the proposed modifications. The implementation and design of the proposed MPPT mechanism is discussed in Chapter Three. Chapter Four presents the experimental results and the discussions derived. The final chapter offers the conclusions drawn from the research.

\section{ELECTROMAGNETISM-LIKE MECHANISM ALGORITHM}

The EM is a population based optimization method proposed by Birbil and Fang [29]. The basic idea of the EM is to imitate the attraction-repulsion mechanism of electromagnetic charges in the effort to find the best global optimal solution in bounded variables. Figure 1 shows an example of the attractionrepulsion search mechanism used in the EM.

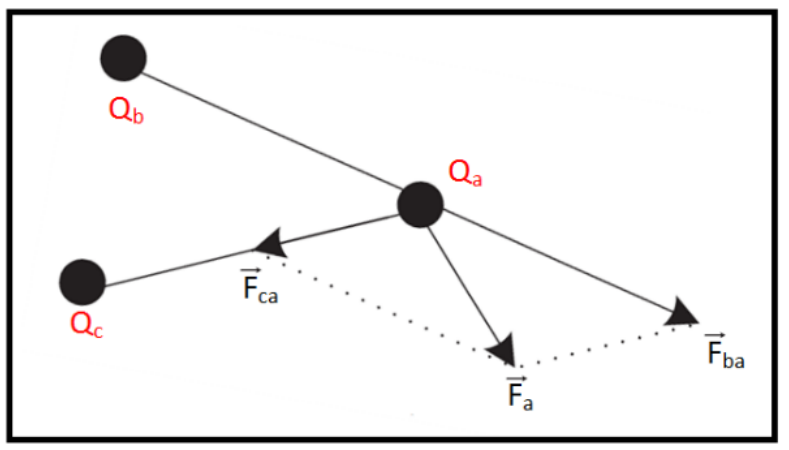

Figure 1. Total force exerted on $\mathrm{Q}_{\mathrm{a}}$ by $\mathrm{Q}_{\mathrm{b}}$ and $\mathrm{Q}_{\mathrm{c}}$

There are several important operations in the EM, including the initialization, local search, charge calculation, force calculation, and movement of particles, as shown in Figure 2. In this research, the adjustment parameter is the rotor speed allowed in the wind turbine. In the algorithm, $m$ sample of initial particles are randomly picked from the feasible PWM value range. Each value of a particle is assumed to be uniformly distributed inside the upper and lower bound. For the purpose of WECS MPPT, the particle with the highest output power is marked as the best particle.

An EM with Split, Probe, and Compare (SPC-EM) feature is proposed in this research. The SPCEM is an enhanced version of the EM which has the ability to hit accurate solutions without heavily slowing down the entire convergence process. The local search mechanism of a conventional EM is replaced with the SPC search procedure. A tuning equation is designed to dynamically regulate the lengths of the probes based on the outcomes of every iteration, as shown in equation (1).

$$
L=\frac{2}{1+\exp \left(\frac{10 i}{\text { Max_LSIte }}\right)}
$$

In equation (1), $i$ indicates the current number of local search iteration while Max_LSIte represents the maximum number of iteration. Figure 3 explains the decision making process of the SPC search mechanism in the form of a flowchart. This enhanced SPC-EM algorithm is then employed as the MPPT scheme of a WECS, which is further explained in the next chapter.

Optimization of wind energy conversion systems - an artificial intelligent approach (Ying Ying Koay) 


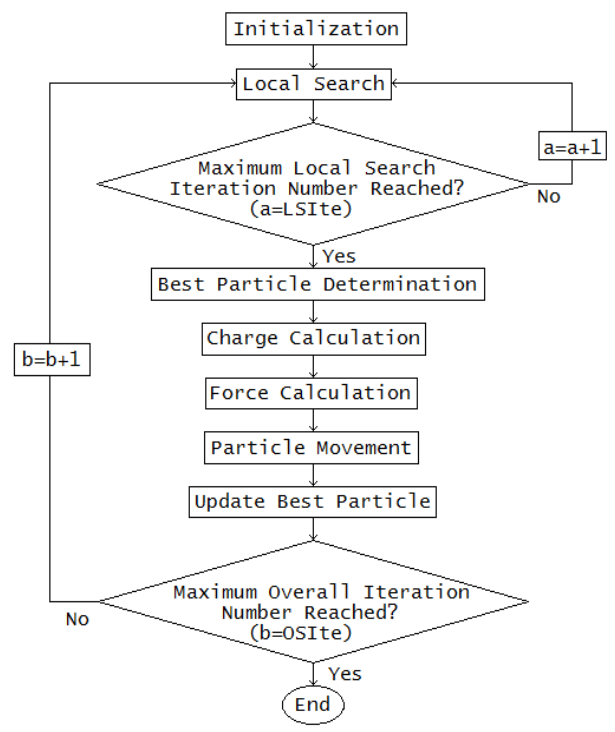

Figure 2. The flow of a conventional EM algorithm, where $a$ and $b$ denote the iteration number of local and global search respectively, while LSIte and OSIte refer to the pre-determined maximum iteration number in local and overall search.

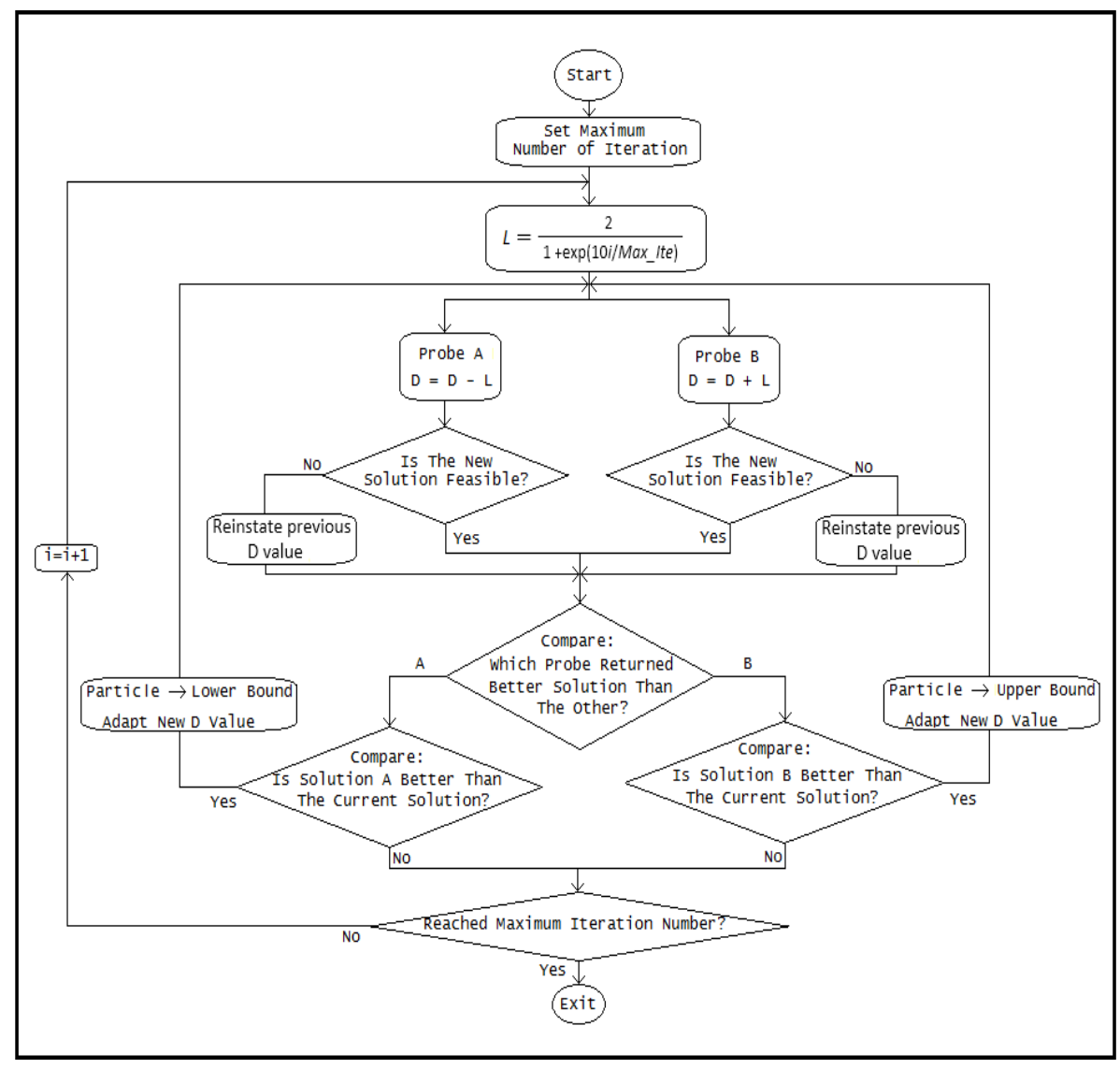

Figure 3. The flow of the proposed SPC-EM, in which $D$ represents the parameter of a particular dimension in a particular solution and $\lambda$ denotes the size of the search step 


\section{MAXIMUM POWER POINT TRACKING}

The aim of the MPPT scheme is to make sure the turbine operates to push the maximum output power possible. In this research, the enhanced SPC-EM is proposed as the MPPT scheme of a WECS. The proposed implementation is as depicted in Figure 4. An adjustable electrical load is added to control the speed of the turbine when needed. The SPC-EM algorithm monitors the power output and electronically controls the dump load by adjusting the pulse-width-modulator (PWM) signal, which in turn controls the speed of the turbine, ensuring the operation to produce the maximum possible output power.

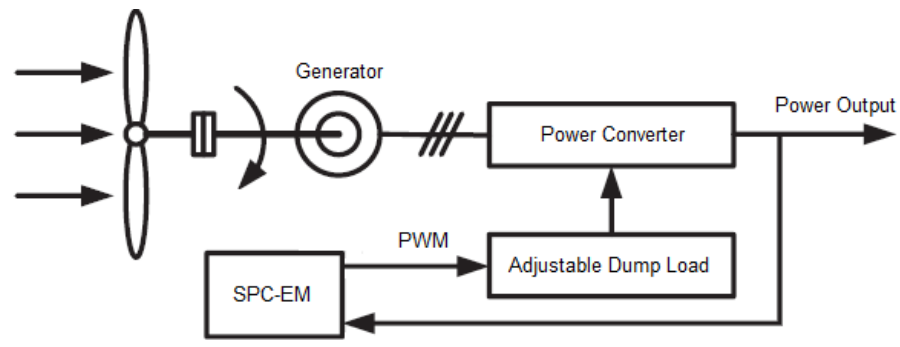

Figure 4. The proposed implementation of SPC-EM as the MPPT scheme of the WECS.

\subsection{Algorithm performance tests}

Simulations are carried out to investigate the performance of the proposed MPPT scheme under different wind profiles. In the simulations, a WECS with $300 \mathrm{~W}$ Permanent Magnet Synchronous Generators is employed. The rated wind speed is set at $12 \mathrm{~m} / \mathrm{s}$. The performance of the proposed SPC-EM is put to test under three different wind profiles simulated individually, as shown in Figure 5. Then, to mimic the ever changing wind speed in the real world application, the simulation of the wind changes from the first profile to the second, and then to the third, to further investigate if the proposed algorithm has the ability to track for the MPP with changing wind speeds.

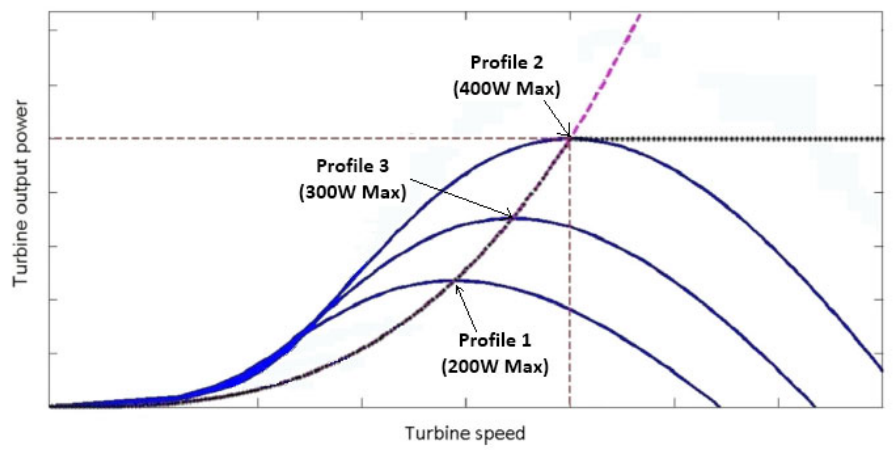

Figure 5. The wind profiles generated to test the proposed SPC-EM.

Simulations are conducted in VB.Net software with Intel 1.6GHz Core i5 processor, 4G RAM and 64-bit Windows 7 operating system. Ten particles are employed in the SPC-EM to track for the MPP. To further study the improvement made by the modified algorithm, the performance of the SPC-EM is benchmarked with that of a conventional EM. 30 individual runs are conducted to avoid stochastic discrepancies. The results are presented in the following chapter.

\section{RESULTS AND ANALYSIS}

The experiments are conducted by testing the performance of the algorithms in tracking the maximum power point in the simulated wind profiles. The results of the 30 individual runs are compared in the forms of best solutions, worst solutions, and average solutions. The standard deviations of the gathered

Optimization of wind energy conversion systems - an artificial intelligent approach (Ying Ying Koay) 
results are also calculated. Table 1 shows the comparison of the results in 3 respective wind profiles. The highest average solutions are highlighted in boldface.

It can be observed from Table 1 that the proposed SPC-EM found higher output powers, which indicates that the SPC-EM managed to hit solutions with relatively higher accuracies. It is also worth noticing the large gap between the best and worst solutions returned by the conventional EM. This inconsistency is caused by the random steps employed in the conventional EM, in which the exploitation of a solution cannot be guaranteed.

Table 1. Comparison of the solutions obtained after 30 individual runs.

\begin{tabular}{ccccc}
\hline & & Profile 1 & Profile 2 & Profile 3 \\
\hline SPC-EM & Best Solution & 200 & 400 & 300 \\
& Worst Solution & 199.94 & 399.9 & 299.91 \\
& Average Solution & $\mathbf{1 9 9 . 9 7}$ & $\mathbf{3 9 9 . 9 2}$ & $\mathbf{2 9 9 . 9 6}$ \\
& SD & $8.26 \mathrm{E}-08$ & $2.74 \mathrm{E}-07$ & $9.33 \mathrm{E}-08$ \\
EM & Best Solution & 199.97 & 399.96 & 299.95 \\
& Worst Solution & 196.01 & 396.82 & 295.01 \\
& Average Solution & 198.79 & 398.09 & 297.62 \\
& SD & $1.25 \mathrm{E}+00$ & $1.72 \mathrm{E}+00$ & $1.64 \mathrm{E}+00$ \\
\hline
\end{tabular}

The convergence processes of the simulations are sampled and compared. Figures 6 (a), (b), and (c) show the comparison of the convergence performances of the algorithms under wind profile 1,2 and 3 respectively. Several things can be observed from the plots. First, the SPC-EM managed to hit relatively higher best output power. Secondly, the SPC-EM also found the final best solutions relatively quicker. Observe the rapid conversion of the SPC-EM at the beginning phase of the convergence processes. The conventional EM, on the other hand, found the best solutions in relatively later iterations.

It can be observed that the proposed SPC-EM performed well in tracking for the maximum output power under different wind profiles. Adopting the advantages of quicker search and higher accuracies, the automatically adjusted search steps enabled the SPC-EM outperform all other benchmarking algorithms.

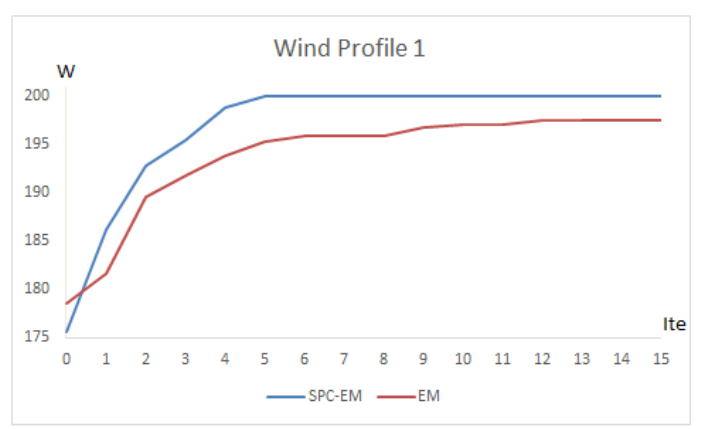

(a)

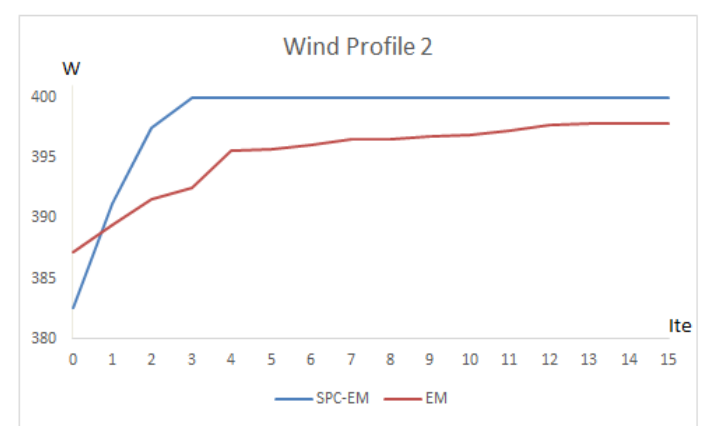

(b)

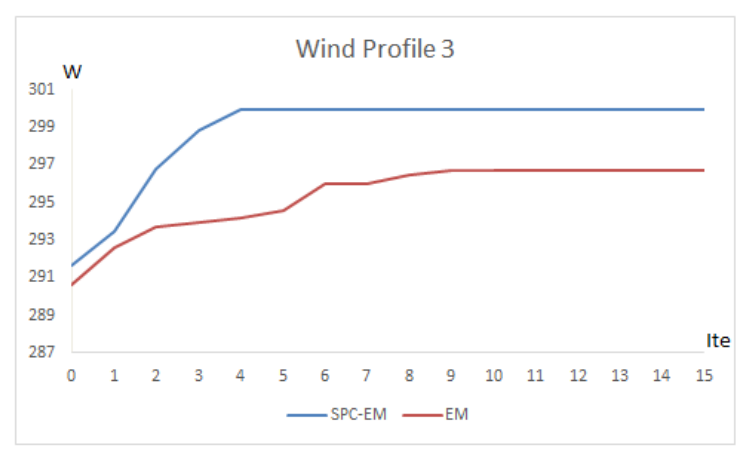

(c)

Figure 6 (a), (b), and (c). Convergence analysis of the algorithms under different wind profiles. 


\section{CONCLUSION}

In this research, an SPC-EM global optimization algorithm is proposed as the MPPT scheme of a micro-WECS. The SPC-EM begins the local search with big steps and dynamically tunes the step size as the search moves on. Experiments and simulations are carried out to test the performance of the proposed SPCEM in tracking the maximum power point under different wind profiles. The results indicate that the SPCEM showed significant improvement over the conventional EM in the benchmarking. It can thus be concluded that based on the simulations, the SPC-EM performs well as an MPPT scheme in a micro-WECS. In time to come, the research will move on to test the SPC-EM in an actual WECS. Implementation of the SPC-EM in other hybrid renewable energy conversion systems is also worth exploring in the future expansion of this study.

\section{ACKNOWLEDGEMENTS}

The authors would like to thank Universiti Tenaga Nasional (UNITEN) for the full support of this research under UNIIG and the BOLD initiative.

\section{REFERENCES}

[1] Liang R-H and Liao J-H, "A fuzzy-optimization approach for generation scheduling with wind and solar energy systems," IEEE Trans Power Syst, vol. 22, 1665-1674, 2007.

[2] Nikolova S, Causevski A, and Al-Salaymeh A, "Optimal operation of conventional power plants in power system with integrated renewable energy sources," Energy Convers Manag; 65: 697-703. 2013

[3] Bansal M, Khatod DK, and Saini RP, "Modeling and optimization of integrated renewable energy system for a rural site," Int Conf Reliab Optim Inf Technol, 25-8. 2014

[4] Böttger D, Götz M, Theofilidi M, and Bruckner T, "Control power provision with power-to-heat plants in systems with high shares of renewable energy sources - an illustrative analysis for Germany based on the use of electric boilers in district heating grids," Energy, vol. 82, pp. 157-167, 2015.

[5] Ghosh SK, Shawon MH, Rahman A, and Nath SK, "Wind energy assessment using weibull distribution in coastal areas of Bangladesh," In: Proceedings of the 3rd International Conference on Developmental Renewable Energy Technology, pp. 1-6, 2014.

[6] Jena D and Rajendran S, "A review of estimation of effective wind speed-based control of wind turbines," Renew Sustain Energy Rev, vol. 43, pp. 1046-62, 2015.

[7] Buehring IK and Freris LL, "Control policies for wind-energy conversion systems," IEE Proc C Gener Transm Distrib, vol. 128, pp. 253-261, 1981.

[8] Houssamo I, Locment F, and Sechilariu M, "Experimental analysis of impact of MPPT methods on energy efficiency for photovoltaic power systems," Int J Electr Power Energy Syst, vol. 46, pp. 98-107, 2013.

[9] Mirbagheri SZ, Mekhilef S, and Mirhassani SM, "MPPT with Inc.Cond method using conventional interleaved boost converter," Energy Procedia, vol. 42, 24-32, 2013.

[10] Bendib B, Belmili H, and Krim F, "A survey of the most used MPPT methods: Conventional and advanced algorithms applied for photovoltaicsystems," Renew Sustain Energy Rev, vol. 45, pp. 637-48, 2015.

[11] Soetedjo A, Lomi A, and Mulayanto WP, "Modeling of wind energy system with MPPT control," Int Conf Electr Eng Informatics, pp. 1-6, 2011.

[12] Ramos-Paja CA, Saavedra-Montes AJ, and Arango E, "Maximum power point tracking in wind farms by means of a multivariable algorithm," Work Eng Appl, pp. 1-6, 2012.

[13] Agarwal V and Aggarwal R, "A novel scheme for rapid tracking of maximum power point in wind energy generation systems," IEEE Trans Energy Convers, vol. 25, pp. 228-36, 2010.

[14] Kesraoui M, Korichi N, and Belkadi A, "Maximum power point tracker of wind energy conversion system," Renew Energy, vol. 36, pp. 2655-62, 2011.

[15] Abdel-Salam M, Ahmed A, and Abdel-Sater M, "Maximum power point tracking for variable speed grid connected small wind turbine," In: Proceedings of the IEEE International Energy Conference Exhibition, pp. 600-605, 2010.

[16] Nahid-Al-Masood Yan R and Saha TK, "A new tool to estimate maximum wind power penetration level: In perspective of frequency response adequacy," Appl Energy, vol. 154, pp. 209-220, 2015.

[17] Hichem H, "A Wind Turbine sensorless Automatic Control Systems, Analysis, Modelling and development of IDA-PBC method," International Journal of Power Electronics and Drive System, vol. 11, no. 1, 2020.

[18] Boureguig K, "Performance Enhancements of DFIG Wind Turbine Using Fuzzy- Feedback Linearization Controller Augmented By High-Gain Observer," International Journal of Power Electronics and Drive System (IJPEDS), vol. 11, no. 1, 2020.

[19] Nour-Eddine TARIBA, Ahmed Haddou, Naima Ikken, Abdelhadi Bouknadel, and Hamid El Omari, "Comparative study of new MPPT control approaches for a photovoltaic system," International Journal of Power Electronics and Drive System (IJPEDS), vol. 11, no. 1, 2020.

[20] Daili Y, Gaubert J-P, and Rahmani L, "Implementation of a new maximum power point tracking control strategy for small wind energy conversion systems without mechanical sensors," Energy Convers Manag, vol. 97, pp. 298306, 2015. 
[21] Wei C, Zhang Z, Qiao W, and Qu L, "Reinforcement learning-based intelligent maximum power point tracking control for wind energy conversion systems," IEEE Trans Ind Electron, vol. 62, pp. 6360-6370, 2015.

[22] Wu P.T, Hung Y.Y, and Lin Z.P, "Intelligent forecasting system based on integration of electromagnetism-like mechanism and fuzzy neural network," Expert Systems with Applications, vol. 41, pp. 2660-2677, 2014.

[23] Tan J.D, Dahari M, Koh S.P, Koay Y.Y, and Abed I.A, "Analysis of the Effect of Search Step Size on the Accuracy and Convergence Properties of Electromagnetism-Like Mechanism Algorithm," J. of Mult.-Valued Logic \& Soft Computing; vol. 28, pp. 429-441, 2017.

[24] Kumar D and Chatterjee K, "A review of conventional and advanced MPPT algorithms for wind energy systems," Renewable and Sustainable Energy Reviews, vol. 55, 957-970, 2016.

[25] Ganjefar S, Ghassemi AA, and Ahmadi MM, "Improving efficiency of two-type maximum power point tracking methods of tip-speed ratio and optimum torque in wind turbine system using a quantum neural network," Energy, vol. 67, pp. 444-453, 2014.

[26] Bianchi FD, Battista HD, and Mantz RJ, Wind turbine control systems: principles, modelling and gain scheduling design. 1sted. London: Springer-Verlag; 2007.

[27] TanakaT and Toumiya T, "Output control by hill-climbing method for a small-scale wind power generating system," Renew Energy, vol. 12, 387-400, 1997.

[28] Datta R and Ranganathan VT, "A method of tracking the peak power points for a variable speed wind energy conversion system," IEEE Trans Energy Convers, vol. 18, pp. 163-168, 2003.

[29] Birbil S.I and Fang S.C, "Electromagnetism-like mechanism for global optimization," Journal of Global Optimization, vol. 25, pp. 263-282, 2003.

Int J Pow Elec \& Dri Syst, Vol. 11, No. 2, June 2020 : 1040 - 1046 